\title{
O "viralatismo" histórico no consenso acerca do fracasso brasileiro: reflexões sobre a urgência da construção de um pensamento crítico por e para as margens.
}

\author{
El "viralatismo" histórico en el consenso acerca del fracaso brasileño: \\ reflexiones sobre la urgencia de la construcción de un pen-samiento \\ crítico por y para las margenes. \\ Historical "viralatismo" in the Brazilian failure consensus: some \\ considerations on the interest of building a thought by and for the margins.
}

\section{Danielle Bezerra de Morais ${ }^{1}$}

\begin{abstract}
Resumo
Este trabalho propõe reflexões sobre o consenso acerca da ideia de fracasso nacional que domina o cenário da crítica sociopolítica brasileira. Comumente elaborada a partir de comparações por contraste, essa ideia do fracasso brasileiro diante das promessas da Modernidade se fundamenta numa naturalização histórica de problemas estruturais complexos. Dócil ao questionar o paradigma ocidental, a crítica dominante é feroz com o que considera ser o elemento-chave do problema: "o brasileiro". Suposta raiz do problema para a qual esses discursos convergem, "o brasileiro" aparece como um tipo social inacabado, devendo, assim, ser educado, moldado, europeizado. Por isso é tão comum o argumento da educação à cidadania aparecer como remédio à ideia de persistência de uma cultura pré-moderna que impediria o progresso e a civilização de florescerem. Problemático, pois contribui para uma opacidade teórica que invisibiliza questões estruturais fundamentalmente modernas e legitima o status quo de desigualdades, esse consenso é sintomático de um viralatismo em grande parte devido a um passado colonial ainda presente. Por essas razões, este trabalho analisará, tendo a questão educacional como fio condutor, discursos que (re)produzem a ideia do fracasso brasileiro desde o século XIX, questionando o ponto cego da crítica dominante. O objetivo é propor, através do arsenal teórico-metodológico pós-colonial, reflexões para a construção de uma crítica sociopolítica brasileira por e para as margens.
\end{abstract}

Palavras-Chave: Viralatismo histórico, Educação à cidadania, Crítica Pós-colonial.

\section{Resumén}

Este trabajo propone reflexiones sobre el consenso acerca de la idea de fracaso nacional que domina el escenario de la crítica sociopolítica brasileña. Comúnmente elaborada a partir de comparaciones por contraste, esa idea del fracaso brasileño ante las promesas de la Modernidad se fundamenta en una naturalización histórica de problemas estruc-turales complejos. Dócil al cuestionar el paradigma occidental, la crítica dominante es feroz con lo que considera ser el elemento clave del problema: "el brasileño". Supuesta raíz del problema para la cual esos discursos convergen, "el brasileño" aparece como un tipo social inacabado, debiendo, así, ser educado, moldeado, europeizado... Por eso es tan común que el argumento de la educación a la ciudadanía aparezca como remedio a la idea de persistencia de una cultura premoderna que impediría el progreso y a la civi-lización de florecer. Es problemático ya que contribuye a una opacidad que hace invisi-bles las cuestiones estructurales fundamentalmente modernas y legitima el status quo de desigualdades, ese consenso es sintomático de un viralatismo, debido en gran parte a un inconsciente colonial subyacente. En consecuencia, este trabajo analizará, tenien-do la cuestión educativa como hilo conductor, discursos que (re)producen la idea del fracaso brasileño desde el siglo XIX, cuestionando el punto ciego de la crítica dominan-te. El objetivo es proponer, a través del arsenal teórico-metodológico poscolonial, refle-xiones para la construcción de una crítica sociopolítica brasileña por y para las márgenes.

\footnotetext{
1 Doutoranda em História do Direito pela Universidade Grenoble Alpes (CERDAP²), em regime de dupla titulação internacional com o Programa de Pós-Graduação interdisciplinar de Humanidades, direitos e outras legitimidades (Diversitas), pela FFLCH da Universidade de São Paulo - SP, Brasil; daniellemorais2310@gmail.com
} 


\begin{abstract}
This work suggests a reflection on intellectual consensus around national failure thought that subjugates Brazilian societal review. Usually structured as a comparison by contrast, Brazilian failure thought, in front of occidental Modernity promises, is based on historical naturalization of a sum of very complex structural issues. Docile when questioning occidental paradigm, the main critique is brutal on what it considers as the problem's key point: "the Brazilian". Presumed root of all evils according to those common speeches' meet, "the Brazilian" appears as an incomplete social kind, that must be educated, civilized, Europeanized... That is why the argument of the education to a well-defined kind of citizenship has its real significance and appears as a cure to a premodern culture persistence which would avoid improvement and civilization ideals to succeed. Problematic situation, since it participates to theoretical opacity which blinds fundamental modern structural issues and legitimates an extreme unfair status quo, this consensus is symptomatic of an historical viralatismo, mainly due to a subjacent colonial subconscious. In this context, this work will analyze talks which (re)build national failure thought starting from XIX century, with education subject as guiding thread, in order to question what seems to be a blind spot in front of dominant critique. The aim is to propose, by means of postcolonial theoretical and methodological arsenal, a reflection allowing to build a Brazilian sociopolitical critique by and for the margins.
\end{abstract}

Key-words: Historical viralatismo, Citizenship education, Postcolonial critique.

\title{
1. Introdução
}

"O Brasileiro herdou a indolência do índio e a malandragem do africano [além de uma] tendência a querer privilégios [...] herdada dos povos ibéricos". Qualquer pessoa concordaria em dizer que essa declaração racista, num tom descomplexado, poderia ter vindo de uma fonte do século 19 ou do início do século 20, quando o cenário político-intelectual era propício a esse tipo de discurso. No entanto, a declaração polêmica do General Antônio Hamilton Mourão ocorreu em agosto de 2018, durante a sua primeira entrevista enquanto candidato à vice-Presidência da República pelo PSL, ao lado do então deputado Jair Bolsonaro. Questionado sobre o conteúdo racista de sua declaração, o general respondeu que não havia nenhum, alegando, em sua defesa, sua ascendência indígena e o fato de que a ideia encontrava respaldo na academia. Tratar-se-ia, segundo ele "de um caldinho cultural [... que constituiria] a realidade que a gente vê em alguns lugares. Isso faz parte do DNA do brasileiro". E conclui dizendo que "[n]ós não temos nenhuma raça pura. Somos uma amálgama dessas culturas”2.

O historiador, cientista político e membro da Academia Brasileira de Letras, José Murilo de Carvalho, nos seus escritos amplamente citados nos trabalhos que tratam da construção histórica da cidadania no Brasil, afirma, em 1986, e reitera, em 2010, que o caminho histórico tomado pelos atores brasileiros na busca por direitos civis, políticos e sociais explicaria o porquê da "República que não foi" (Carvalho, 2004). Segundo o autor, o tipo de cidadania e de cidadãos engendrados no Brasil seria baseado na "estadania"

2 Cf. https://oglobo.globo.com/brasil/vice-de-bolsonaro-diz-que-brasileiro-herdou-indolencia-do-indio-malandragem-doafricano-22955042 
(Carvalho, 2010, p. 61), resultado da inversão da ordem das conquistas históricas desses direitos. A consequência teria sido a impossibilidade de se desenvolver um regime representativo - nos moldes ingleses, com um legislativo forte -, devida, em grande parte, à apatia dos cidadãos brasileiros.

Respondendo à "questão brasileira", o antropólogo Roberto Damatta argumenta, num livro onde o mesmo pretende "saber o que faz do brasil, o Brasil" (1997, p. 17), que o ideário da Modernidade não teve êxito no Brasil por causa da existência de uma cultura pré-moderna. Residual, porém, muito presente, a persistência dessa herança pré-moderna seria, segundo Damatta, uma marca da cultura brasileira que a diferenciaria das nações ocidentais e impediria a modernidade de florescer.

Os discursos desses intelectuais renomados, cuja obra é apresentada como "referência obrigatória para qualquer estudo sobre a realidade brasileira" (Damatta, 1997), constituem um recorte particularmente ilustrativo de uma crítica bastante difundida no pensamento social brasileiro. Essa crítica se apoia numa sorte de naturalização histórica que reforça a opacidade de algumas problemáticas fundamentalmente modernas ${ }^{3}$.

Explicar o que faz do brasil, o Brasil, a partir de supostas raízes históricas e culturais apresentadas como sendo próprias à sociedade brasileira e que impediriam a concretização da Modernidade, sem, ao mesmo tempo, interrogar-se sobre as implicações desse paradigma moderno ao qual se aspira quase desesperadamente, implica em conferir um certo tom de fatalidade a numerosas e complexas desigualdades interseccionalmente estruturadas. Além disso, tal posicionamento reatualiza um discurso que, tempos atrás, assumia pressupostos abertamente elitistas, racistas e coloniais.

Consensual, no topo da crítica sociopolítica contemporânea, esse discurso é marcado por um “culturalismo” que autores como Jessé Souza se obstinam a denunciar (Souza, 2000; 2012; 2018). Com efeito, por trás de suas intenções críticas, o perigo desse consenso consiste em (re)produzir uma opacidade teórica que invisibiliza questões estruturais da Modernidade, contribuindo para a legitimação do status quo.

Quanto à forma, o discurso se organiza, quase sistematicamente, numa relação de “comparação por meio de contrates e contradições [...com as nações-modelos]" (Damatta, 1997, p. 19), que sugere a ideia cada vez mais enraizada de fracasso brasileiro. Ora, veremos adiante que esse modus operandi não é nem raro, nem novo.

A obra monumental de Rui Barbosa constitui um exemplo particularmente interessante para iniciar esta análise. Trata-se do seu Relatório e Projeto de Reforma do Ensino Primário e várias instituições complementares da Instrução Pública, apresentado pela primeira vez à

\footnotetext{
${ }^{3}$ No sentido de que essas questões extrapolam as fronteiras brasileiras e se originam no próprio paradigma moderno.
} 
Câmara dos Deputados durante a sessão do dia 12 de setembro de 1882, publicada nos Annaes Parlamentares em 1883. Nesse documento de 1265 páginas e quatro tomos, o deputado e intelectual, na condição de relator da Comissão parlamentar da Instrução Pública do Império, desenvolve a sua longa crítica da sociedade brasileira, cruzando questões que, além de indissociáveis, continuam em voga: a educação nacional e as questões políticas, econômicas e sociais. A crítica e o projeto que a acompanha se apoiam em uma comparação dialética entre das teorias e políticas educacionais brasileiras e aquelas produzidas pelas nações "mais avançadas" (Barbosa, 1947, p. 144). O interessante é perceber que desejo de compreender as causas do suposto fracasso já estava presente no momento da formação nacional e da afirmação do Estado. Já nessa época, o objetivo das reformas era de elevar a nação, de cima para baixo, a um grau superior da escalada civilizacional através da educação.

A recorrência dessa retórica, ainda que sob formas variadas, é sintomática de um profundo mal-estar que a sociedade brasileira deve, em grande parte, ao seu passado colonial. Compreender esse mal-estar, que consiste em silenciar ou minimizar uma série de relações de poder de ordem sócio-histórica, econômica, política e cultural, colocando a culpa do atraso do país em uma categoria que se essencializa como O brasileiro, parece ser uma porta de entrada judiciosa para abordar, a partir de um outro ângulo, esse quebra-cabeça complexo.

Assim, este trabalho propõe uma reflexão sobre os interesses teóricos e sócio-políticos do que chamaremos doravante de pensamento ou retórica do fracasso. Para tanto, utilizaremos o arsenal teórico-metodológico dos estudos pós-coloniais ou decoloniais, notadamente a partir do conceito de inconsciente colonial, de Franz Fanon, que, no contexto brasileiro tomará a forma de complexo de vira-latas.

Uma analise de discursos da inteligência brasileira ao longo da história visa a interrogar esse consenso que sugere que se a Modernidade não floresceu no Brasil, foi ou porque não soubemos adaptar o exemplo das grandes nações; ou por não termos escolhido o melhor modelo ocidental ${ }^{4}$; ou, ainda, porque não estamos prontos para modelos civilizacionais tão avançados.

A conclusão mais ou menos explícita desses discursos é, muito frequentemente, a (re)afirmação de que se o Brasil é o que é, ou seja, se não funciona como deveria, é por causa dos brasileiros. Essa categoria, mais comumente designada no singular ( $O$ brasileiro ou $O$ povo brasileiro), à qual se destina, ao mesmo tempo, repreensões e preocupações por parte de autoridades diversas, sofre um múltiplo escalonamento de alteridade. $O$ brasileiro, evidentemente, não é nem $O$ europeu ou $O$ americano que se tem por referência, nem o

\footnotetext{
${ }^{4} \mathrm{Na}$ falta de um melhor termo para designar as civilizações que serviram, historicamente, de modelo para os agentes brasileiros, a palavra "ocidental" e seus derivados servirão para designar as nações europeias centrais, como a França, a Inglaterra e a Alemanha, e os Estados-Unidos.
} 
"híbrido 5 " produzido pela colonização e encarnado pelos grupos que se percebem e se autoproclamam como elites periféricas. Trata-se do Outro que não é bom o suficiente por si e que, consequentemente, precisa ser educado, modernizado, civilizado, politizado, europeizado...

Nesse contexto, o argumento educacional aparece com toda a sua força, consistindo em um ponto de análise particularmente fecundo para compreender essa relação de alteridade, razão pela qual esse será o fio condutor desta demonstração. O discurso em torno da educação à cidadania e à uma ideia precisa de participação política será usada como passarela para relacionar as principais questões suscitadas pelos defensores da retórica do fracasso.

Partiremos, então, do cenário da crítica social do século 19 até a virada do século 21 , no intuito de analisar os pontos comuns de alguns desses discursos de autoridade. O objetivo é compreender em que medida essa retórica do fracasso, sintomática de um inconsciente colonial subjacente, persiste, e quais são as suas consequências no horizonte políticointelectual brasileiro.

Para responder a essas questões, analisaremos, num primeiro momento, discursos que contribuem para reforçar a ideia de fracasso nacional (2) e, num segundo momento, interrogaremos o que parece ser um ponto cego desse consenso, de modo a pensarmos alternativas para uma crítica sociopolítica por e para as margens (3).

\section{A atualização de um pensamento do fracasso nos discursos político-intelectuais da crítica social brasileira}

De onde vem a ideia de fracasso? Quais são os critérios de tal veredito? Assim como a construção da identidade, a do consenso em torno da ideia de fracasso brasileiro também se dá por comparação, principalmente, por contraste. Desse modo, examinar essa técnica discursiva parece ser um caminho determinante para compreendermos os fundamentos do pensamento ou retórica do fracasso. Para tanto, analisaremos as formas esposadas por essa técnica de comparação dialética, tão corrente quanto antiga, na crítica sociopolítica brasileira (2.1.), a fim de compreendermos como ela contribui para cristalizar uma ideia de fracasso nacional assaz sintomática de um persistente viralatismo histórico (2.2.).

\subsection{O papel da comparação dialética na renovação constante de uma hierarquização dos povos}

\footnotetext{
${ }^{5}$ Híbrido seria aquele que, segundo Bhabha, posiciona-se entre os termos da oposição binária de colonizador e colonizado, em eco ao «entre » de Derrida. No entanto, o hibrido de que tratamos não constituirá necessariamente um instrumento de desconstrução do discurso dominante, mas ao mesmo tempo o seu objeto e reprodutor (Haddour, 2006, p. 153).
} 
Se os discursos considerados progressistas no século 19 assumiam abertamente um posicionamento baseado na redução biológica e racial de determinados povos e categorias sociais (2.1.1.), verificaremos em que medida esse tipo de essencialização sobrevive nos discursos contemporâneos, ainda que sob formas mais ou menos sutis (2.1.2.).

\subsubsection{Na esteira dos grandes povos: a comparação dialética como argumento irrefutável na retórica do século 19}

No Brasil oitocentista, os debates intelectuais e políticos foram marcados por concepções herdadas das correntes positivista, evolucionista, naturalista, realista e racionalista. Esse turbilhão de ideias, cuja circulação foi favorecida pelas ondas de imigração cada vez mais intensas, a partir da segunda metade do século, teve um impacto considerável sobre a forma como a nação recém-independente projetou seu futuro sócio-político, suas instituições e, evidentemente, o sistema educacional que as apoiaria.

Esse arsenal científico e ideológico determinou, em grande parte, a marcha e o tom empregados na "ampla reforma social, [...levada a cabo por agentes brasileiros com o intuito de] melhorar o aspecto físico, moral e mental da 'raça nacional'." (Stepan apud Souza, 2008, p. 146). Os pressupostos dessa corrente declaradamente eugênica eram símbolo de "evolução, progresso e civilização, termos que constituíam o imaginário nacionalista das elites brasileiras." (Idem). Em razão de suas pretensões preventivas, tal corrente inspirou vários projetos de reforma, especialmente na aérea jurídica, educacional e da saúde ${ }^{6}$.

No terreno educacional, reina a fé na ciência como vetor do progresso, em razão da considerável importância atribuída ao Positivismo, sobretudo às ideias de Auguste Comte e seus discípulos, por autoridades intelectuais e políticas extremamente influentes. É nesse cenário que se inscreve Rui Barbosa, figura emblemática da elite político-intelectual do século 19. A aposta na educação como remédio para todos os males do país é impregnada pela herança iluminista que atravessa toda a sua obra, mas, particularmente, o texto da Reforma do Ensino Primário e várias instituições complementares da Instrução Pública.

Movido por essa fé, Rui Barbosa insiste, junto aos "espíritos progressistas" (Barbosa, 1883, 1947, p. 18) de seu tempo, na necessidade de acelerar o desenvolvimento da instrução pública, de modo a acompanhar a expansão incessante da população e a "[ultrapassar], por meio de reduções consideráveis e cada vez mais amplas [do analfabetismo], o déficit primitivo". (Ibid., sic, p. 18).

\footnotetext{
${ }^{6}$ As políticas de saúde compreendiam tanto as questões ligadas à medicina quanto à higiene doméstica e pública.
} 
Para que seus pares se dessem conta da evidente necessidade de instruir minimamente as massas iletradas, o deputado opera uma demonstração tão longa quanto documentada, recorrendo à técnica da comparação dialética em cada ponto de sua argumentação. De um lado, ele apresenta os exemplos teóricos e as práticas educacionais das "civilizações avançadas" (Ibid., p.139), do outro, a "realidade desgraçada" e a "miséria" (Ibid., p. 69) atestadas pelos números oficiais da educação brasileira. Para justificar a técnica, o autor argumenta que a avaliação da população nacional pela educação, tal qual ele a apresenta, segue uma "tendência universal" (Ibid., p. 85). Assim, a experiência das "nações mais esclarecidas" (Ibid., p. 167) não apenas justificaria a necessidade das políticas educacionais brasileiras, mas também a forma e os objetivos que estas deveriam conter.

Desse modo, em se tratando de instrução elementar, o Estado deveria necessariamente se encarregar de sua organização, pois, como ele explica, se na Inglaterra, nação superior e orgulhosa de ser liberal, seria preciso deixar "inevitavelmente ao governo o papel preponderante no desenvolvimento da educação popular" (Ibid., p. 107), no Brasil, não poderia ser diferente.

Nesse mesmo sentido, o reformador julga indispensável que a gratuidade proclamada pela Constituição de 1824 seja fortalecida pelo caráter compulsório da escolarização das crianças. Curioso é perceber que a discussão acerca da legitimidade jurídica da instrução obrigatória não ocorra, sob o pretexto de que se tratava apenas de uma "lucubração meramente didática" e de um "supérfluo esforço" (Ibid., p. 184). De fato, ele parte do postulado de que não há necessidade de demonstrar a legitimidade da medida, pois "o que revela mostrar, é que este princípio é hoje vitorioso, por assim dizer, em toda a superfície do universo civilizado, e que, segundo a mais irrefragável das induções experimentais, não há possibilidade de instrução popular sem a sanção da coercitividade legal” ( Idem, sic).

Para justificar a adoção do princípio de secularização do ensino público, Rui Barbosa lança mão do mesmo artifício. Os críticos que apelidam a escola laica de "escolas sem deus" são desqualificados não por argumentos, mas tão-somente pelo exemplo inglês. A garantia de que as críticas não se sustentam viria do simples fato que "[...] esta ideia prevalece no país onde a religião é mais honrada". Quanto às formas e aos limites deste princípio para Barbosa, a escolha se dá entre os modelos francês e americano, sendo esse último preferido em virtude de seu caráter mais moderado (Ibid., p. 308). A mesma estratégia discursiva é mantida até o final do seu projeto de mais de mil páginas.

De fato, Rui Barbosa apenas segue a tendência de seu tempo. Na sessão parlamentar do dia 7 de maio de 1888, seu contemporâneo, o deputado e intelectual Joaquim Nabuco, considerado outro grande nome da história, procura convencer os seus pares hesitantes, às 
vésperas da aprovação da lei que aboliria a escravidão, através da representação de uma França mítica, "exemplo da história contemporânea" (Nabuco, 1889, p. 09). Assim como os alemães ocupavam o solo francês, Joaquim Nabuco apresenta a escravidão como o inimigo que ocupava o solo brasileiro. O intuito era buscar na bravura dos franceses a inspiração necessária para se liberar do inimigo nacional. Seguindo o exemplo da "França [que] esteve disposta a dar a ultima gotta de seu sangue, ella ofereceu o ultimo soldo de suas economias para apressar o mais immediatamente possivel a evacuação do território; comprou á vista a sua libertação, por um sacrifício que admirou o mundo inteiro, e que fez renascer a confiança perdida na vitalidade da nação franceza e no destino da raça latina", o Brasil não poderia recuar diante do seu inimigo. E conclui: "É o exemplo que eu ofereço à nação brazileira", pouco antes de ser calorosamente aclamado (Idem, sic).

Hão de argumentar, contudo, que Rui Barbosa e Joaquim Nabuco eram homens de um tempo ultrapassado, pois as críticas da pós-modernidade teriam desconstruído irrevogavelmente essa concepção ocidentalocêntrica do Homem, do sentido da história e do poder desmesurado da instrução para a perfectibilidade da humanidade. É o que verificaremos por meio da análise dos discursos de alguns autores assaz representativos da inteligência brasileira do século 20 até o inicio do 21 .

\subsubsection{A comparação dialética: uma técnica em voga nos discursos da crítica social contemporânea}

A circulação de ideias positivistas no século XIX preparou o terreno para o desenvolvimento fecundo das correntes evolucionista e higienista no cenário políticointelectual brasileiro do século 20 .

No livro de publicação póstuma intitulado Os africanos no Brasil $^{7}$, Nina Rodrigues ${ }^{8}$ pretende trazer um ponto de vista científico sobre a "questão de higiene social" que é o “problema 'o negro' no Brasil”, colocando os seus contemporâneos "face a face com a esfinge do futuro [brasileiro]" (Rodrigues, 2004, p. 17). Através de um estudo das práticas culturais dos povos africanos trazidos por meio do tráfico, o objetivo era de deduzir, a partir de uma abordagem biológica, histórica e etnográfica, a relação entre "O negro" e a criminalidade, bem como os efeitos da miscigenação no futuro da formação racial da nação. Nina Rodrigues justifica a necessidade de se pensar como "homens de ciência e patriotas, nos corretivos que

\footnotetext{
${ }^{7}$ Segundo informações do prefácio escrito por Homero Pires, o livro já estava quase pronto no momento da morte de Nina Rodrigues, em 1906. Oscar Freire, um de seus discípulos, toma para si a tarefa de terminar o faltava do livro para proceder a sua publicação.

${ }^{8}$ Nina Rodrigues (1862-1906) é considerado o fundador da antropologia criminal e dos estudos sobre a cultura negra no Brasil, por meio de uma abordagem conhecida pelo seu racismo, cientificismo e nacionalismo.
} 
se podem opor às más consequências" (Ibid., p. 21) da iminente e temida extinção da raça branca, face ao "sentimentalismo criminoso" (Ibid., p. 24) ensejado durante a luta contra a escravidão, que ele saúda, mas que teria atribuído ao "negro", "ex autoritate própria, qualidades, sentimentos, dotes morais ou ideias que ele não tinha" (Ibid., p. 17).

Logo nas primeiras páginas, o exemplo estrangeiro da "imigração negra"( Ibid., p. 21) é invocado, ao mesmo tempo, para diferenciar os critérios de análise, notadamente através das diferenças climáticas que explicariam adaptações diferenciadas das duas raças em países do norte e do sul das Américas, mas também para expor ao "brasileiro patriota, a evocação dolorosa do contraste maravilhoso entre exuberante civilização canadense e norte-americana e o barbarismo guerrilheiro da América Central.” (Ibid., p. 23).

Fundamentados os pressupostos da tese a ser defendida pelo autor, a comparação é retomada já na primeira linha do desenvolvimento. Trata-se de cotejar a formação racial brasileira à estadunidense. Para Nina Rodrigues, enquanto nos Estados Unidos, a "raça negra" encontrava-se "sitiada pela raça branca, que se abstém, quanto pode, de cruzar com ela [fazendo com que a primeira se encontre] isola[da] no Black Bell do Sul e centro da grande federação", [...] na América Latina, em particular no Brasil, a raça negra, predominando muitas vezes pela superioridade numérica, incorporou-se à população local no mais amplo e franco mestiçamento" (Ibid., sic, p. 27). Por isso, lamenta o autor, a solução para o problema “o negro” torna-se ainda mais complexa no Brasil. E explica que, como a segregação não foi tão bem mantida quanto nos Estados-Unidos, a fórmula genérica do "coloured men" não se aplicaria à análise nacional, posto que a miscigenação teria ensejado um tratamento específico da questão, devendo, portanto, "discrimin[ar] as capacidades relativas de civilização e de progresso" de negros e mestiços (Idem).

Seguindo o mesmo projeto de perfectibilidade social, Oliveira Viana analisa o problema das instituições políticas brasileiras através da comparação com as "nações evoluídas". No seu livro, Instituições Políticas Brasileiras. Metodologia do Direito Público: os problemas brasileiros da ciência politica, o autor explica porque as elites brasileiras não conseguem resolver o problema do "povo-massa", como o haviam feito as grandes nações europeias e estadunidense (Viana, 1974, p. 17).

Monteiro Lobato, por sua vez, utiliza o argumento estrangeiro para combater as resistências nacionais ao desenvolvimento capitalista, por meio de uma perspectiva de conquista bastante provocadora. Em uma de suas conferências pelo Brasil, o autor afirma que, na busca do progresso, cuja direção e o ritmo são postos pelos povos evoluídos, "[o] mundo é de quem pode, e só pode quem progride". E acrescenta que “[o] índio perdeu estas terras para o português porque, como não progredia, não podia." (Lobato, 2010, p. 36), além de 
completar com a seguinte provocação: “[...] não somos nada no concerto dos povos. Somos, quando muito, o que muito bem diz o hino: 'Um gigante deitado em berço esplêndido'. Ora, isso dum país viver deitado em caminha de criança é, além de ridículo, extremamente perigoso", pois "o País que vive deitado em berço esplêndido não escapa de mudar de dono.” (Ibid., pp. 35-36).

É importante ressaltar que os representantes dessa crítica social dos séculos XIX e XX, como Nina Rodrigues e Monteiro Lobato, foram extremamente criticados por uma grande parte dos pensadores contemporâneos. Aliás, em sua época, o tom explícito e provocador não constituía uma unanimidade na exposição de leituras sociais que legitimam a hierarquização dos povos e das populações racializadas.

Este é o caso, por exemplo, de Sérgio Buarque de Hollanda. Considerado um autor incontornável das ciências sociais, Hollanda também recorre diversas vezes à técnica comparativa no seu clássico Raízes do Brasil. O retrato do brasileiro típico encarnado no "homem cordial", que, como explica Jessé Souza, seleciona apenas os aspectos negativos do "homem plástico e emotivo de [Gilberto] Freire" (Souza, 2018, p. 15), sugere uma relação direta entre seu "intimismo" (Hollanda, 2009, p. 149) e a incapacidade de ultrapassar "vínculos familiares demasiado estreitos" (Ibid., p. 144) com os obstáculos ao desenvolvimento de uma sociabilidade moderna.

Hollanda explica, ainda, que "[a] manifestação normal de respeito em outros povos tem aqui sua réplica, em regra geral, no desejo de estabelecer intimidade. E isso é tanto mais específico quanto se sabe do apego dos portugueses, tão próximos de nós, aos títulos e sinais de reverência." (Ibid., p. 148). Esse desejo que se manifesta nas relações que contrariam os códigos urbanos ocidentais, suscita estranhamento junto aos estrangeiros que o vivenciam, complementa o autor. Para exemplificar sua ideia, Hollanda invoca a história de um comerciante da Filadélfia que teria mostrado "seu espanto ao verificar que, no Brasil, como na Argentina, para conquistar um freguês, tinha necessidade de fazer dele um amigo" (Ibid., p. 149).

A construção discursiva e os exemplos selecionados por Hollanda reforçam a ideia de inadequação brasileira ao que Rui Cunha Martins chama de "modelo moderno de fronteira", referindo-se à tendência dos povos ocidentais a romper com as instâncias de sociabilidade consideradas privadas para construir outra que as ultrapasse, segundo os códigos impessoais da nação, quiçá da humanidade (Martins apud Boto, 2017, p. 382).

Nesse mesmo sentido, o autor pretende demonstrar a falta de polidez dos brasileiros por meio da comparação de suas práticas com aquelas usuais "entre os japoneses, onde, como se sabe, a polidez envolve os aspectos mais ordinários do convívio social", enquanto "nossa 
forma de convívio social é, no fundo, justamente o contrário da polidez" (Hollanda, 2009, p. 147). Além do que é dito, os silêncios são fecundos elementos de análise. A ausência de definição para o termo "polidez" ou de uma forma qualquer de relativização de seus critérios é relevadora da concepção etnocêntrica adotada pelo autor, já que a polidez aparece como um valor ou prática universal, uma vez que é apresentada como algo que não carece de explicação.

Quanto à concepção de Estado igualmente ditada por parâmetros ocidentais, sob a forma burocrática weberiana, Hollanda é categórico: "falta tudo a ordenação impessoal que caracteriza a vida no Estado burocrático" (Ibid., p. 146). Esse critério da ausência, da falta de impessoalidade das relações sociais brasileiras, é o que estruturará a crítica sociológica enunciada, tempos depois, por Roberto Damatta. Na esteira de Freire e Hollanda, Damatta argumenta que o problema brasileiro residiria na oposição de "um sistema dual [,onde,] de um lado, existe o conjunto de relações pessoais estruturais, sem as quais ninguém pode existir como ser humano completo; [e,] de outro, há um sistema legal, moderno, individualista (ou melhor: fundado no indivíduo), modelado e inspirado na ideologia liberal burguesa." (Ibid., p. 24).

Os exemplos de discursos intelectuais e políticos que se apoiam nesse tipo de comparação dialética são tão numerosos que um único estudo não poderia pretender exaurilos, principalmente, no espaço de um artigo. O que se pode constatar, contudo, a partir de sua persistência e do fato dessa técnica não sair de moda, é o seu caráter sintomático. De fato, isso revela reminiscências, na crítica social contemporânea, de uma concepção hierarquizada dos povos e de certos grupos sociais. Essa concepção, como veremos adiante, contribui significativamente para a cristalização do pensamento do fracasso brasileiro. Enfim, como falar de fracasso induz a buscar as causas, eis algumas delas, segundo autores de grande renome no debate intelectual brasileiro.

\subsection{A cristalização da ideia de fracasso brasileiro pelos detentores da palavra pública}

Educar $O$ brasileiro para elevá-lo ao nível dos grandes povos: eis o objetivo convergente da crítica dominante no Brasil, ainda que a temática da educação das massas não seja uma especificidade brasileira9 ${ }^{9}$

A constatação da impossibilidade de implantação bem-sucedida do conjunto de práticas e valores da Modernidade ocidental, nessa parte da periferia do mundo, leva a

\footnotetext{
${ }^{9}$ Sobre a crítica ocidental da racionalidade dos povos, vide: Jacques Rancière. La haine de la démocratie. Paris: La Fabrique. 2005; Jacques Rancière Jacques. Le maître ignorant: cinq leçons sur l'émancipation intellectuelle. Paris: Fayard, 1987; Francis Dupuis-Déri. Démocratie, histoire politique d'un mot: aux États-Unis et en France. Montréal (Québec): Lux. 2013.
} 
inteligência brasileira a pensar as suas causas. O fracasso é explicado, principalmente, pela incapacidade brasileira de adaptar o modelo sociopolítico das "grandes nações" (2.2.1.), ou pela escolha do modelo ocidental equivocado (2.2.2.) ou, ainda, pela pura impermeabilidade da população ao progresso (2.2.3.).

\subsubsection{A ideia da incapacidade brasileira na adaptação do ideal moderno republicano}

No livro intitulado Cidadania no Brasil: o longo caminho, José Murilo de Carvalho denuncia as causas do fracasso brasileiro na busca da cidadania. Já na introdução, ele anuncia que o Brasil errou o caminho no momento em que a ordem das conquistas históricas de direitos que compõem a cidadania foi invertida. Para Carvalho, a valorização dos direitos sociais antes dos civis, por ele considerados indispensáveis para o fortalecimento da participação política, ensejou uma "tradição [política...] que buscava melhorias por meio de aliança com o Estado, por meio de contato direito com os poderes públicos". Atitude que, para o autor, "seria mais bem caracterizada como 'estadania'.” (Carvalho, 2010, p. 61).

Ainda que Carvalho conclua dizendo que "[s]eria tolo achar que só há um caminho para a cidadania”, ele pondera que é "razoável supor que os caminhos diferentes afetem o produto final, afetem o tipo de cidadão e, portanto, de democracia que se gera. Isto é particularmente verdadeiro quando a inversão da sequência é completa, quando direito sociais passam a ser a base de pirâmide.” (Ibid., p. 221). Em suma, a ausência de organização política da sociedade civil, oriunda da forma como os direitos históricos foram adaptados pelos atores brasileiros, constituiria o "tropeço" histórico que teria impedido o sucesso da democracia liberal.

Esse discurso, reverberado por republicanos de campos ideológicos diversos, repousa, constantemente, sobre a seguinte ideia: as elites nacionais falharam ao colocar em prática o projeto republicano. No campo educacional, as teses, livros e artigos que partem da mesma premissa são extremamente numerosas.

Para explicar os problemas ligados à educação popular, por exemplo, é raro que a historiografia da educação não condene a descentralização operada pelo Ato Adicional de 1834, sob o Império, e reiterada em 1889, pela primeira Constituinte republicana, como um tropeço decisivo para o insucesso do projeto educacional, necessariamente idealizado enquanto política de Estado. O grande pecado apontado é o consequente retardamento na política de centralização da questão educacional, na contramão das políticas progressistas implementadas no "primeiro mundo". 
A crítica feminista brasileira em matéria de educação adota, majoritariamente, o ponto de vista do feminismo ocidental, segundo o qual o acesso tardio das mulheres à educação formal e, consequentemente, ao direito de voto, constituiu um dos maiores obstáculos ao seu processo emancipatório. Raros são os casos que criticam essa receita ocidental de emancipação, de quem se retêm a mensagem de inclusão, sem, contudo, salientar que as exclusões como a de gênero são próprias a esse mesmo modelo.

Num artigo que problematiza a "sacralização de algumas chaves de leitura e hipóteses explicativas" por uma memória nacional da escola republicana, Alessandra Schueler e Ana Maria Magaldi pontuam que esta vertente historiográfica contribui para a "afirmação e atualização de uma memória de desalento e de decepção causadas pelo suposto fracasso e/ou omissão do regime republicano no âmbito educacional - memória que (re)inventa a ideia de uma República que não foil "' (Schueler e Magaldi, 2009, sic, pp. 33-34),

Paralelamente a essa análise que lamenta a adaptação imperfeita ou inacabada do modelo sociopolítico liberal, há outra leitura da realidade social brasileira que, ao invés de apontar a má adaptação como causa do fracasso, prefere a hipótese da escolha do modelo ocidental errado.

\subsubsection{A ideia da incapacidade brasileira na escolha do "bom modelo": o ressentimento de uma crítica de esquerda}

Fazendo um balanço sobre as reformas educativas implementadas na primeira República, Taís Delazane conclui sua dissertação lamentando o atraso nacional quanto ao debate e à concretização de um sistema nacional de educação:

Muito embora já não se discutisse a validade da idéia de universalização do direito de todos à educação, um preceito transplantado para Brasil no âmbito das ideologias do movimento de Independência, vindo da Europa, onde os esforços de implantação da educação popular já registravam uma longa história: com a edificação dos Estados Nacionais, a educação popular já aparecia como corolário da afirmação dos direitos do homem, essencial à formação cívica e patriótica do cidadão. (Delazane, 2007, p. 153)

A descentralização da competência legislativa e orçamentária em matéria de ensino primário e secundário, operada em 1834, aparece constantemente como a grande vilã da história da educação nacional e da formação da cidadania no Brasil.

Apesar da proximidade com a crítica liberal sob vários pontos, inclusive quanto à defesa de centralização do ensino pelo poder público, o cavalo de batalha da crítica da esquerda republicana é a educação popular. Como para os liberais, a educação formal, a consciência de direitos e a educação para o voto aparecem como degraus indispensáveis à

\footnotetext{
${ }^{10}$ Com grifo das autoras, o termo é uma referência direta ao livro de José Murilo de Carvalho, intitulado Os bestializados : $O$ Rio de Janeiro e a República que não foi, publicado pela primeira vez em 1987.
} 
concretização da cidadania. Para esta corrente, a negligência com a educação popular é um projeto de dominação implantado desde a Independência, em resposta a interesses externos e às contradições de classes internas (Xavier, 1980). Geralmente abordada sob um prisma socioeconômico e postulando uma visão dialética do processo histórico, a questão da educação popular - ausente ou de qualidade inferior - é encarada como projeto das elites destinado a impedir a emancipação das massas.

Há, também, os defensores de uma crítica radical ao aparelho educacional do Estado. A título de exemplo, Tatiana da Silva Calsavara, em sua tese de doutorado, traz a lume algumas experiências político-pedagógicas do movimento anarquista no início do século 20 , sob a influência das teorias revolucionárias vindas da Europa (Calsavara, 2002), a fim de relançar o debate sobre modelos educacionais alternativos ao liberal. Embora o projeto educacional defendido por essas vertentes possua um claro propósito emancipatório, o modelo europeu, ainda que marginal, continua servindo de referência.

No caso da crítica marxista, são muitas as divergências, contudo, para muitos, a solução para o fracasso brasileiro estaria no sucesso do modelo socialista. Nesse sentido, é curioso observar que a partir da queda do bloco soviético, essas críticas que, em geral, eram dirigidas às elites econômicas e políticas, no final do século 20 , passam a se reportar ao indivíduo. Tido como vítima até pouco tempo, o indivíduo e o tão demonizado individualismo passam a ser culpados pela despolitização criada pelo sistema capitalista e responsável pela sua manutenção.

\subsubsection{A ideia da incapacidade brasileira ou por que não "dar pérolas aos porcos"}

Ao escutarmos os discursos cada vez mais unívocos na condenação do Brasileiro, a ideia que ecoa é que o "povo-massa" (Viana, 1974, p. 17) seria, no fim das contas, o grande problema que a avant-garde brasileira - seja ela de direita ou de esquerda - não soube compreender corretamente, como o afirmava Oliveira Viana.

O autor explica que na organização das nossas instituições políticas, seria preciso encarar nosso povo objetivamente, pois sem levar em conta os elementos constitutivos da cultura popular, todos dos esforços das elites locais para levar a cabo o projeto de modernização do país seriam vãos. E completa, ao defender uma educação voltada para necessidades práticas de uma sociedade moderna: “[o] Brasileiro, enquanto analfabeto, raciocina corretamente [dando provas de um] inalterável fundo de sensatez, que lhe vem da raça superior originária. Deem-lhe, porém, instrução; [...] [e façam-lhe] uma pergunta 
concreta [...e] ele nos olha atônito, num estado de imbecilização sonambúlica [...] ou divaga sobre conhecimentos teóricos desconexos" (Ibid., pp. 18-19).

Quanto à questão política, naturaliza a essência cultural do Brasileiro, ao explicar que o povo age "em perfeita concordância com o seu passado histórico, com a sua estrutura social e com a sua psicologia política. São nossas elites que estão iludidas, exigindo dele o que exigem." (Ibid., p. 177). Assim, sem conhecer as massas, seria impossível achar os meios mais aptos para reformá-las em sua estrutura ou em sua mentalidade política, ou seja, no seu “comportamento na vida pública, que é o objetivo das reformas" (Idem).

Trata-se do Brasileiro, nos moldes da representação retrógrada feita por Rui Barbosa, utilizando o personagem de Monteiro Lobato, o Jeca Tatu, numa conferência sobre a Questão Social e Política no Brasil, em março de 1919, durante a sua primeira campanha presidencial. "Conheceis, por ventura, o Jeca Tatu, dos Urupês, do Monteiro Lobato, o admirável escritor paulista?", interpela o público. Para facilitar a resposta, ele adianta que se trata "[d]aquele tipo de uma raça, que, 'entre as formaduras da nossa nacionalidade', se perpetua, 'a vegetar, de cócoras, incapaz de evolução e impenetrável ao progresso'?” (Barbosa, 1956).

É a ideia de Brasileiro que Hollanda ajuda a cristalizar através do "homem cordial", emotivo, regido por um "tipo primitivo [das relações do meio rural e da] família patriarcal”, distante das “"boas maneiras’ [que significam] civilidade”. Aquele arquétipo cuja polidez não passa de um "disfarce” para o seu caráter "intimista". (Hollanda, 2009, p. 145; 147; 149; 150). É o Jeca Tatu mais apegado aos sentimentos do que à razão.

Ao Brasileiro, a crítica dominante parece preferir o povo reclamado por Aristides Lobo, no momento da proclamação da República. Um povo que talvez não tivesse permanecido apático diante da instituição de um regime oligárquico, a despeito do seu consentimento. Há quem defenda mesmo que o problema viria da ausência de povo, conforme à visão do mesmo evento histórico pelo francês Louis Couty, contemporâneo de Aristides Lobo. Uma declaração onde o mesmo afirma que "o Brasil não tem povo", avaliando a situação através de seus próprios pressupostos culturais tomados como universais, figura na introdução do livro de José Murilo de Carvalho (Couty apud Carvalho, 2004, p. 10).

Tal é o povo que Cavalho defende, em parte, quando condena o etnocentrismo e o elitismo dos referidos observadores participantes dos oitocentos, descritos, contudo, como “pessoas esclarecidas e interessadas nas mudanças sociais e políticas", mas que o autor termina abandonando às mesmas críticas severas. Numa tentativa de distanciamento do que define como visão maniqueísta da relação "de mão dupla, embora não necessariamente equilibrada" entre o Estado e o cidadão, Carvalho explica que tratá-la como um mal necessário ou negá-la por completo teria por consequência a bestialização do povo. E termina 
responsabilizando "a apatia dos cidadãos" como sustentáculo do sistema que os oprime (Carvalho, 2004, pp. 10-11).

Por fim, em sua obra mais recente, o autor volta ao problema central da cidadania, argumentando que "[a] ausência de uma população educada tem sido sempre um dos principais obstáculos à construção da cidadania civil e política." (Carvalho, 2010, p. 11). Esse tipo de diagnóstico consensual reverbera a ideia que Jacques Rancière combate incessantemente em sua obra intitulada Ódio à democracia; ideia esta que sugere que "se a ciência não consegue se impor, é por causa da ignorância. Se o progresso não consegue progredir, é por causa dos retardatários" (2005, p. 87).

O Brasileiro: eis a causa mais consensual do fracasso nacional. Essa ideia de povo que os autores precitados contribuem - voluntária ou involuntariamente - para renovar é combatida por vozes minoritárias como a do sociólogo Jessé Souza. Uma grande parte da produção cientifica desse autor se destina a desconstruir, a partir do conceito de "capital simbólico" de Pierre Bourdieu, essas novas formas de essencialização no pensamento social dominante que, quanto ao fundo, são bastante antigas.

O pensamento social brasileiro se encontra, via de regra, encurralado num lugar social próprio às relações ambivalentes dos povos colonizados. No caso do Brasileiro, a essas ambivalências, acrescentam-se níveis de subalternidade cada vez mais complexos, na medida em que fatores de exclusão se intersectam numa realidade de "modernização seletiva" (Souza, 2005, pp. 94-95). Por isso, pensar essas ambivalências a partir de outros ângulos parece essencial para compreendermos o ponto cego da crítica dominante.

\section{O ponto cego do viralatismo brasileiro: reflexões para ultrapassar o pensamento do fracasso}

Ao questionar o consenso intelectual sobre a crise da democracia (palavra à qual se acrescenta o adjetivo "representativa" para dar algum sentido, face a contradição das práticas por ela designadas), o filósofo político francês Jacques Rancière demonstra de que modo a produção discursiva dos defensores desse consenso fornece uma base científica para um projeto político.

No caso brasileiro, Schueler e Madaldi atacam o mesmo discurso a partir da questão educacional, mostrando como ele serve para reforçar a ideia de fracasso por meio de uma narrativa que sugere uma "omissão do regime republicano", reinventando a ideia de uma "República que não foi, que não cumpriu suas promessas de extensão dos direitos da cidadania, que não se tornou efetivamente uma res publica, uma coisa de todos, com um 
governo para e por todos: aquela que permanece, ainda hoje, inconclusa, inacabada." (Schueler e Magaldi, sic, 2008, p. 34).

O esforço para ultrapassar essa ideia-força, no Brasil, é duplo. Não se trata apenas de estabelecer uma crítica geral da Modernidade e de suas instituições, de modo a problematizar a crença em suas vantagens absolutas, é preciso levar em conta uma formação colonial que ainda está longe de ser ultrapassada no pensamento nacional. Por isso, interrogaremos, a partir do conceito de inconsciente colonial, o ponto cego dessa retórica do fracasso (3.1.), antes de propormos algumas pistas reflexivas para ultrapassá-la e construir um pensamento crítico voltado para a potência (3.2.).

\subsection{O inconsciente colonial no consenso acerca do fracasso brasileiro}

“Por 'complexo de vira-latas' entendo eu a inferioridade em que o brasileiro se coloca, voluntariamente, em face do resto do mundo." (Rodrigues, 2013, s/n). Eis a definição do termo cunhado por Nelson Rodrigues, em 1958, numa crônica esportiva a respeito da vitória da seleção brasileira na Copa do mundo, sedeada pela Suécia. Tal expressão, que indica o "problema de falta de fé em si mesmo" (Idem) ganha sentidos diversos nos discursos da crítica social brasileira. Reinterpretada, deformada e instrumentalizada por agentes de diferentes segmentos ideológicos, a expressão tornou-se cada vez mais difundida. Muito embora não se adira, neste artigo, à ideia de voluntarismo sugerida por Nelson Rodrigues, a expressão e seus derivados são interessantes enquanto ferramenta de análise para a compreensão do inconsciente colonial presente nos discursos dominantes.

Assim, parece-nos essencial entender por que esse complexo de vira-latas é uma peçachave da retórica do fracasso brasileira (3.1.1.) e em que medida ele pode ajudar a identificar os obstáculos para uma necessária descentralização da questão social (3.1.2.).

\subsubsection{O inconsciente colonial, uma peça-chave do pensamento do fracasso brasileiro}

Embora o ponto comum seja o indivíduo - e o que se chama de individualismo -, o que a crítica social dominante no Brasil tem de diferente da que faz sucesso no Norte Global é o tipo de indivíduo apresentado como problemático. Com efeito, a ideia ilustrada pelos discursos analisados na primeira parte deste trabalho insinua que o Brasileiro, razão do fracasso nacional, peca duplamente ao querer se tornar um indivíduo pós-moderno antes mesmo de ter-se modernizado. Ora, a ideologia do desenvolvimento (ou do progresso) que anima até mesmo algumas das teorias emancipatórias mais revolucionárias supõe o respeito de um certo número de regras e, sobretudo, de ordem, no sentido de etapas e de hierarquia. A 
hipótese aqui defendida é de que a persistência dessa concepção evolucionista dos indivíduos e da sociedade ajuda a explicar por que o Brasileiro é encarado como um tipo social inconcluso e por que as elites locais se voltam sistematicamente para o Norte ${ }^{l 1}$, desde a formação nacional, na esperança de encontrarem o remédio para o fracasso brasileiro.

Analisando a ideia de inconsciente colonial de Frantz Fanon, Azzedine Haddour explica que o colonizado, aqui encarnado pelo Brasileiro, é um "sujeito apoiado sobre duas culturas e excluído das duas ao mesmo tempo" (Haddour, 2006, p. 144). Ainda que a persiga incansavelmente, tal sujeito é excluído da cultura europeia, da qual ele se distancia seja pela aparência física, em razão da mestiçagem lamentada por Nina Rodrigues; seja pela pelas suas maneiras pré-modernas típicas do "homem cordial" de Hollanda; seja, ainda, pela genuína incapacidade política denunciada por Oliveira Viana.

Quando as três razões se combinam nos discursos das elites periféricas, materializa-se o estereótipo imortalizado pelo Zeca Tatu, de Monteiro Lobato. Nesse caso, à exclusão de uma "cultura originária europeia", acrescenta-se a exclusão da própria cultura brasileira; ou seja, daquela que se reivindica moderna, urbana, próxima da europeia pela ascendência e pelas práticos, tradicionalmente associada ao centro-sul do país. A cultura do Jeca Tatu vem acompanhada do adjetivo "popular" ou "regional", isso quando não é designada como folclore. Seu exotismo só é apreciado em pequenas doses e dentro de circunstâncias precisas. É este o Brasileiro visado pelos projetos pedagógicos das elites benevolentes, destinados a educar, modernizar, civilizar e, em alguns casos, até mesmo a operar o fetiche persistente do "branqueamento da raça'12".

A ideia de assimilação, defendida por Albert Memmi, no seu livro Retrato do Colonizador, Retrato do Colonizado, ajuda a compreender as ambivalências presentes nas sociedades marcadas pelo colonialismo. Trata-se, segundo Memmi, de um processo de alienação baseado em níveis de privilégios e, consequentemente, de subalternidade. A assimilação se dá, portanto, entre sujeitos das camadas dominantes que, mesmo sendo explorados pelo sistema colonial, não param de elogiá-lo. A razão desse comportamento aparentemente contraditório provém do fato deles serem, ao mesmo tempo, opressos e beneficiados por esse sistema, pois conservam a sua condição de "dominantes para dentro, [ainda que permaneçam] dominados de fora" (Memmi, 1985; Galeano, 2010, p. 19).

Ora, a própria legitimidade das elites periféricas repousa no senso comum incessantemente alimentado de que elas são as mais aptas, por sua proximidade do centro, a

\footnotetext{
${ }^{11}$ A palavra Norte, aqui, é adota tanto o sentido de Norte Global, de Ocidente, quanto de direção a seguir.

${ }^{12}$ A declaração foi do Vice-Présidente da República, o General da reserva Hamilton Mourão, então candidado à época, em outubro de 2018. $C f$. : https://noticias.uol.com.br/politica/eleicoes/2018/noticias/2018/10/06/mourao-cita-branqueamento-daraca-ao-falar-que-seu-neto-e-bonito.htm
} 
encontrar a melhor forma de adaptação do modelo ocidental de civilização para salvar a nação periférica do atraso e do fracasso. Assim, é preciso observar, sob outra perspectiva, a recorrência da utilização de comparações pela crítica social dominante e o objetivo civilizador que lhe é subjacente, notadamente na questão educacional, legitimando a "expansão enraizada do desejo de colonizar, de converter o outro em algo idêntico, mas subordinado" (Slater apud Nunes, 2001, p. 57). Trata-se de perceber que os defensores da retórica do fracasso também se encontram encurralados nesse lugar social de assimilação, motivo pelo qual não veem interesse ou não conseguem ver além do horizonte instransponível da Modernidade ocidental.

\subsubsection{O deslocamento do olhar crítico face a um viralatismo histórico}

O cerne do pensamento do fracasso baseia-se na crença segundo a qual o modelo de sociedade moderna funcionou nos países que o instituíram, mas não tem funcionado no Brasil. Assim, a constatação do fracasso se dá, necessariamente, por comparações por contraste, propagando uma verdadeira fé. Fé na superioridade do Outro cobiçado ou, como dizia Nelson Rodrigues, "problema de fé em si mesmo", legitimado pelo "culturalismo" que vem se substituir ao "racismo científico" no discurso da inteligência brasileira (Souza, 2018, p. 10). O problema dessa crença, é que se a premissa é falsa, a conclusão também o é. $\mathrm{Na}$ crítica à Modernidade, de uma forma geral, raros são aqueles que problematizam os seus fundamentos e implicações, abordando, normalmente, questões superficiais que não vão às raízes do problema. Esse exercício torna-se ainda mais complexo no caso brasileiro, pois tal atitude contestadora necessitaria deixar de lado o viralatismo do pensamento do fracasso e questionar, ao mesmo tempo, o modelo e a civilização que o forjou. Em outras palavras, a grande dificuldade consistiria, antes de tudo, em desconstruir um fetiche secular em torno da superioridade cultural europeia e da glorificação da história estadunidense.

Trata-se de um exercício extremamente difícil, uma vez que deve ser feito por legatários de instituições, práticas morais e religiosas, formas de produção e de validação do conhecimento e até mesmo de uma autopercepção ditada pelo olhar externo. Difícil, porém necessário e urgente, é "repensar o Brasil sem o uso de categorias implicitamente racistas contra o próprio povo" (Souza, 2018, p. 23) e "desnaturalizar o centramento", "que oculta uma visão limitadora e [...] fechada" (Nunes, 2001, p. 57).

Essa dificuldade explica, em partes, a rejeição de ideias e metodologias que combatem essa herança colonial atualizada pela retórica do fracasso. Outra razão da insistência nesse “culturalismo conservador” (Souza, 2000) reside na possibilidade confortável de permanecer 
à sombra do Ocidente, quando se reivindica uma postura crítica, posto que os exemplos do "primeiro mundo" costumam dispensar grandes esforços argumentativos.

Dessa forma, reflexões consideradas demasiado exóticas são imediatamente (des)qualificadas como retrógradas ou utópicas, dependendo do grau de simpatia que suscitam. A crítica de Jacques Rancière aos discursos que desqualificam as lutas populares pela instituição de uma democracia autêntica, em oposição ao regime de oligarquias eletivas, traz uma reflexão interessante. São esses discursos que "permitem interpretar todo movimento de luta contra a despolitização, operada em nome da necessidade histórica, como manifestação de uma fração retrógrada da população ou de uma ideologia ultrapassada" (Rancière, 2005, p. 95).

No mesmo sentido, a inteligência brasileira segue procurando meios para reparar as falhas de modelos civilizacionais apresentados como uma necessidade histórica - criticados, mas ardentemente desejados - com o intuito de encontrar a melhor forma de adaptá-los a realidade brasileira, ou, na maior parte dos casos, de adaptar a realidade brasileira ao modelo idealizado. Raras são ainda as críticas que ousam desviar o olhar e espiar além do horizonte instransponível da Modernidade.

\subsection{Quebrando o ciclo da impotência: reflexões sobre um pensamento por e para as margens}

Como já ficou claro, na retórica do fracasso, o Norte é sempre o Ocidente! E não somente no sentido geográfico do termo. As discussões por trás dessa retórica giram, via de regra, em torno dos obstáculos históricos, culturais, sócio-políticos, e econômicos que impedem o projeto moderno de florescer e das possíveis soluções para a sua adaptação. Raros sãos os esforços no sentido de construir uma alternativa brasileira para as questões do Brasil. Por isso, nesse cenário disputado por discursos carregados de implicações políticas, ainda que devidamente cobertos pelo verniz da neutralidade científica, é preciso lançar mão de ferramentas teórico-metodológicas que possibilitem uma descentralização do olhar (3.2.1.), de modo a viabilizar reflexões sobre uma crítica propositiva por e para as margens (3.2.2.).

\subsubsection{As lentes pós-coloniais: olhando além do horizonte da modernidade}

Não podemos tratar o processo colonial, ao analisarmos as condições atuais dos povos que o sofreram, como um elemento isolado do passado ou como se essa violência histórica não tivesse uma estreita relação com a formação das identidades, memórias e políticas no presente. Banhadas numa cultura colonial que sedimentou, ao longo dos séculos, uma forma 
específica e homogeneizante de se conceber a organização social e política, além da própria produção do saber, é preciso entender que as sociedades colonizadas contemporâneas têm de desafiar dogmas poderosos. Por isso, é mister examiná-las a partir de um espectro mais amplo, a exemplo da proposta crítica pós-colonial.

Os estudos pós-coloniais, também chamados de decoloniais, enquanto movimento teórico, apareceram, inicialmente, nos campos disciplinares da crítica literária e da antropologia. A iniciativa foi encabeçada, principalmente, por intelectuais culturalmente e politicamente marcados pela dominação colonial britânica e teve grande repercussão nas universidades estadunidenses, além de estar-se desenvolvendo em vários países da América Latina.

Frequentemente interpretado como marcador cronológico, o prefixo "pós", embora ambíguo, não se refere ao período ulterior às ocupações dos territórios colonizados. Trata-se, na verdade, de uma crítica radical que visa promover uma verdadeira ruptura no campo epistemológico e no das práticas políticas. Como explica Béatrice Colignon, contrariamente aos ataques que lhes tem sido direcionados, "o projeto [defendido pelos estudos póscoloniais] não é de promover uma inversão [do dominação sofrida pelos povos e categorias subalternizadas], e sim uma mudança radical das formas de relações entre todas as partes do mundo, redefinindo-as, eventualmente" (Colignon, 2007, p. 02). "Pós" significa, portanto, romper, ultrapassar.

No campo histórico, o caminho frequentemente adotado pela crítica pós-colonial tem operado dois movimentos complementares: de um lado, procede-se à denúncia dos "esquecimentos", dos silêncios e das naturalizações realizadas por uma tradição historiográfica dominante, de outro, tenta-se descentralizar o olhar da história, abrindo-se para pontos de vista diversos acerca de atores sócio-históricos pouco convencionais, trazendo uma riqueza de narrativas sobre o fato colonial. Esse é apenas um método de análise entre vários outros dessa corrente heterogênea, mas são os pontos que gostaríamos de enfatizar neste artigo.

Trazer à tona o viés colonial da narrativa histórica dominante toca no ponto essencial do verniz de neutralidade por ela ostentado e que a protege de críticas. É extremamente necessária essa desconstrução dos discursos científicos que legitimam a dominação simbólica - mas também política e econômica - das relações entre o centro e a periferia, tanto entre povos, no âmbito internacional, quando entre grupos sociais, no interior das sociedades colonizadas como o Brasil.

Além da denúncia, o papel do descentramento também é crucial, pois abre espaço para que categorias subalternizadas se tornem mais audíveis, para a diversidade de objetos e, 
sobretudo, de sujeitos que disputam as narrativas históricas, o que é essencial para ultrapassar o paradigma colonial. Fala-se de paradigma porque "se trata de uma forma global de pensamento, que vai muito além da ordem política ligada ao período histórico do colonialismo" (Idem), e se funda num agenciamento do mundo entre Europeus e os Outros.

Retomando as palavras de Julien Rajaoson, "[os] afrescos propostos pela historiografia ocidental em vigor ocultam literalmente o papel exercido pelos subalternizados na história das sociedades colonizadas, muito embora essa categoria social seja a mais exposta à pobreza causada pela ordem internacional" (Rajaoson, 2018, p. 16).

O fato de a crítica pós-colonial ter ocupado os espaços acadêmicos, servindo-se das tribunas universitárias e exprimindo-se em línguas de alcance mundial - em razão da expansão cultural colonialista, diga-se de passagem - conferiu-lhe uma visibilidade crescente nas ultimas décadas. No entanto, as reações são muitas e ferozes. Longe de ser acolhida pela ortodoxia acadêmica, essa corrente tem lutado para penetrar o campo das ciências sociais e humanas, dominados por uma visão ocidentalocêntrica tanto nos antigos impérios coloniais, quanto nas antigas colônias.

A rejeição é ainda maior quando, além de criticar o discurso dominante, ousa-se propor às elites intelectuais que elas "aprendam com o Sul", no sentido empregado por Boaventura de Souza Santos. A expressão refere-se à necessidade defendida por uma parte da crítica pós-colonial de se introduzir na bolha acadêmica, outras epistemologias, fontes, formas de/e saberes e metodologias, rejeitados pela ortodoxia em nome de uma ideia de "pureza científica" pouco sustentável.

\subsubsection{Os modelos alternativos de organização sociopolítica: pensando uma saída pelas} margens

"Quando o português chegou. Debaixo de uma bruta chuva. Vestiu o índio. Que pena! Fosse uma manhã de sol. O índio tinha despido. O português". No seu célebre poema Erro de português, Oswaldo de Andrade enfatiza, brilhantemente, a ambiguidade do termo "português". Enquanto a estrutura gramatical remete à ideia de erro como desrespeito da língua culta, o conteúdo se refere ao desrespeito da cultura local pelo colonizador.

O desejo de partir desse poema para refletir sobre soluções alternativas para problemas de diversas ordens no cenário brasileiro provém da ideia de possibilidades outras que ele suscita. Imaginar formas de ruptura com o paradigma colonial, vencendo o viralatismo histórico que o alimenta, supõe abrir-se para aprender com outros modos de organização sociopolítica. Alguns desses exemplos podem ser encontrados na diversidade étnica e cultural 
do próprio território brasileiro ou no dos povos vizinhos, que também tentam resistir ao paradigma colonial.

Para tanto, todavia, é preciso vencer um duplo desafio. O primeiro, reside na solidez de um sistema social escalonado em classes econômicas e simbólicas, imposto pelo paradigma colonial, o qual, por sua vez, determina em grande parte o único modelo político mundialmente legitimado. Os fundamentos, via de regra, são os mesmos em todos os lugares que o adotam, e se apoiam na ideia de representação política. O próprio edifício da representação baseia-se, por sua vez, na crença compartilhada na competência diferenciada dos representantes eleitos para escolherem as melhores soluções para os problemas coletivos. Desse modo, tanto no Brasil quanto no dito "primeiro mundo", a identificação entre erudição e capacidade de decisão por trás do argumento da competência invalida abordagens que sugiram que teríamos lições sociopolíticas interessantes a aprender com grupos sociais que não se enquadram nos critérios de audibilidade do paradigma ocidentalocêntrico.

O segundo desafio reside no viralatismo criado pelo escalonamento em níveis de subalternidade nas relações entre povos e categorias sociais. $\mathrm{O}$ pensamento brasileiro reproduz uma racionalidade vira-latas baseada na dupla relação de alteridade explicada acima, e a razão pela qual a comparação adquire todo o seu sentido é sempre o Outro. Tratase "[d]o Outro que serve de modelo ou de referência, que legitima ações ou que impõe silêncios, aquele a quem se imita ou coloniza" (Nóvoa apud Cantini in Rego, 2011, p. 44). Por isso, ao estabelecer indicadores ou fundamentar decisões de impacto sociopolítico com base em comparações dialéticas, age-se num campo de poderes onde as relações de centro e periferia se organizam e cujos limites são determinados pelas práticas discursivas. Encurralado entre $O$ Outro do centro e o da periferia, o pensamento do fracasso mostra-se incapaz de perceber alternativas nas experiências de povos ou grupos sociais historicamente qualificados como primitivos.

Do ponto de vista político, por exemplo, é extremamente necessário e urgente descentralizar a narrativa histórica sobre a democracia, quebrando, a partir de exemplos históricos, a crença segundo a qual as experiências democráticas, enquanto práticas políticas, só teriam existido na Europa Antiga ${ }^{13}$. Sobre o mesmo tema, a antropologia política também fornece ferramentas fecundas para revisitar essa questão.

\footnotetext{
${ }^{13}$ A título de exemplo, o historiador e cientista político canadense Francis Dupuis-Déri traz a lume uma série de exemplos de práticas democráticas existentes em épocas e lugares que não são convencionalmente lembrados quando se fala de democracia, como os noticiados pelos colonizadores ao chegarem nos territórios situados no lugar que se tornaria o Norte das Américas, após a invasão inglesa e francesa; ou ainda na Nigéria, durante a ocupação inglesa, mas também de algumas comunas da França na Idade Média, época pouco lembrada por experiências democráticas. $C f$. Francis Dupuis-Déri. Démocratie, histoire politique d'un mot: aux États-Unis et en France. Montréal (Québec): Lux. 2013.
} 
Do ponto de vista educacional, como explica Vera Maria Ferrão Candau, é preciso mesclar políticas de igualdade com políticas de diferença, no sentido de respeito às diferentes cosmovisões e formas de pensar novas perspectivas de humanização (Candau, 2016, p. 17). Por isso, "[d]ecolonizar significa, no campo da educação [mas também no da política], uma práxis baseada numa insurgência educativa propositiva, portanto, não somente denunciativa por isso o prefixo "DE" e não "DES" - onde o termo insurgir representa a criação e a construção de novas condições sociais, políticas e culturais do pensamento", desvencilhandoo das amarras coloniais (Oliveira, 2016, p. 39).

Vasta é a produção pós-colonial latino-americana, ainda que não tenha atingido a visibilidade que merece. Os rastros das potências coloniais do Norte Global não nos servem, quando se trata de pensar novas formas de emancipação. Aprender com o Sul, tornar obsoleta a indagação ainda atual de Spivak, "Pode o subalterno falar?" (Spivak, 2014), eis um caminho pelo qual talvez possamos iniciar o processo de ruptura com o paradigma moderno colonial, à condição de ultrapassarmos o viralatismo histórico que impede todo pensamento de potência de se enraizar no terreno da crítica social brasileira.

\section{Referências}

BARBOSA, R. Reforma do Ensino Primário e várias instituições complementares da Instrução Pública (1883), Obras completas, Ministério da Educação e Saúde, Volume X, Tomos 1, 2, 3 e 4. Rio de Janeiro: Typographia Nacional. 1947.

BOTO, C. Instrução pública e projeto civilizador. O século XVIII como intérprete da ciência, da infância e da escola, São Paulo, Editora Unesp, 2017, 428 p. (Obra completa)

CAlSAVARA, T. S. Práticas da educação libertária no Brasil. A experiência da Escola Moderna em São Paulo. 2002, 271 p. Tese (Doutorado em Educação) - Faculdade de Educação da Universidade de São Paulo, São Paulo. 2002.

CANDAU, V. M. F. Educação descolonizadora: construindo caminhos, Nuevamérica, v. 149, Buenos Aires, 2016, pp. 4-17.

CARVAlHO, J. M. Cidadania no Brasil. O longo caminho, $13^{\text {a }}$ edição, Rio de Janeiro, Civilização Brasileira, 2010, p. 236. (Obra completa)

CARVAlHO, J. M. Os bestializados. O Rio de Janeiro e a República que não foi, $3^{\mathrm{a}}$ edição, CIA das Letras, São Paulo, (1987) 2004, 196 p. (Obra completa) 
COLIGNON, B. Notes sur les fondements des postcolonial studies. EchoGéo, v. 1, juin/août, 8 p. 2007.

DAMATTA, R. Carnavais, Malandros e Heróis. Para uma sociologia do dilema brasileiro. $6^{\text {a }}$ edição. Rio de Janeiro: Rocco, 1997, 350 p. (Obra completa)

DELAZANE, T. As Reformas educacionais de Benjamim Constant (1890-1891) e Francisco Campos (1930-1932): o projeto educacional das elites republicanas. 2007, 224 p. Dissertação (Mestrado em Educação) - Programa de Pós-Graduação em Educação da Universidade Federal de São Carlos, São Carlos. 2007.

DUPUIS-DERI. F. Démocratie, histoire politique d'un mot: aux États-Unis et en France. Montréal (Québec): Lux. 2013. (Obra completa)

GALEANO, E. As verias abertas da América Latina. Porto Alegre: L\&PM Pocket. 2010. 396 p. (Obra completa)

HADDOUR, A. Fanon dans la théorie postcoloniale. Les Temps Modernes. (n ${ }^{\circ}$ 635-636). p. 136-158. 2006/1.

HOLlANDA, S. B. Raizes do Brasil. 26a edição. São Paulo: Cia das Letras. 2009. 220 p. (Obra completa)

LOBATO, M. Conferências, artigos e crônicas. Jaguaré - SP : Ed. Globo. 2010. 243 p. (Obra completa)

NABUCO, J. Extinção da escravidão. Discussão na Câmara dos Deputados e no Senado : desde a proposta do governo até a sanção da Lei $n^{\circ} 3353$ de 13 de maio de 1888, Rio de Janeiro : Imprensa Nacional. 1889.

OLIVEIRA, L. F. O que é uma educação decolonial. Nuevamérica. Buenos Aires, v. 149, p. 35-39, 2016.

RANCIERE. J. La haine de la démocratie. Paris: La Fabrique. 2005. (Obra completa)

RANCIERE, J. Le maître ignorant: cinq leçons sur l'émancipation intellectuelle. Paris: Fayard, 1987. (Obra completa)

REGO, T. C. et al. (orgs.), Memória, História e escolarização. Petrópolis - RJ: Vozes. São Paulo: Revista de Educação. Ed. Segmentos. 2011. (Obra completa) 
RODRIGUES, N. Os africanos do Brasil. $8^{a}$ edição. Obra póstuma [1933]. Brasília: Ed. UnB, 2004. 315 p. (Obra completa)

RODRIGUES, N. Crônica: Brasil vacila entre o pessimismo mais obtuso e a esperança mais frenética. S/n. In: A Pátria de chuteiras. Rio de Janeiro: Ed. Nova Fronteira Participações S.A. 2013.108 p.

RAJAOSON, J. Généalogie de la Philosophie des Lumières : de Nietzsche à la pensée postcoloniale. Revista Brasileira de Estudos da Presença. Universidade Federal do Rio Grande do Sul. (à paraître, halshs-01702801). 19 p. Fev. 2018.

SCHUELER, A. F. M; MADALGI, A. M. B. M. Educação escolar na Primeira República: memória, história e perspectivas de pesquisa. Tempo. Revista do Departamento de História da UFF. v. 26, p. 32-55. 2009.

SOUZA, J. A dimensão simbólica do capitalismo moderno: para uma teoria crítica da modernização. Revista Estudos Políticos. v. 5, p. 41/59. 2012.

SOUZA, J. A modernização seletiva. Brasília: Ed. Da UNP. 2000. (Obra completa)

SOUZA, J. Subcidadania brasileira: para entender o país além do jeitinho brasileiro. Rio de Janeiro: LeYa. 2018. P. 287 p. (Obra completa)

SOUZA, V. S. Por uma nação eugênica: higiene, raça e identidade nacional no movimento eugênico brasileiro dos anos 1910 e 1920. Revista Brasileira de História da Ciência. Rio de Janeiro.v. 1, n. 2, p. 146-166. jul/dez 2008.

SPIVAK, G. C. Pode o subalterno falar? Belo Horizonte: Ed. UFMG. 2014. 174 p. (Obra completa)

VIANA, O. Instituições Políticas Brasileiras. Metodologia do Direito Público: os problemas brasileiros da ciência política. Volume II. $3^{\text {a }}$ edição. Rio de Janeiro: Record Cultural. 1974. 182 p. (Obra completa)

XAVIER, M.E.S.P. Poder político e educação de elite. São Paulo: Cortez. 1980. 144 p. (Obra completa) 